\title{
Brain metastasis from oesophageal adenocarcinoma
}

\author{
Nwabundo Nwankwo, ${ }^{1}$ Aibek E Mirrakhimov, ${ }^{1}$ Kenneth P Wind, ${ }^{2}$ Nora Bucher ${ }^{1}$
}

${ }^{1}$ Department of Internal Medicine, Saint Joseph Hospital, Chicago, Illinois, USA ${ }^{2}$ Department of Pathology, Saint Joseph Hospital, Chicago, Illinois, USA

\section{Correspondence to} Dr Aibek E Mirrakhimov, amirrakhimov1@gmail.com

\section{DESCRIPTION}

A 74-year-old man with a medical history of hypertension, hypercholesterolaemia was diagnosed with distal oesophageal adenocarcinoma in June 2009. Prior to that the patient unintentionally lost $15 \mathrm{~kg}$ in 5 months and had difficulty swallowing both solids and liquids. An Oesophagectomy was performed, and he was subsequently treated with adjuvant chemotherapy including carboplatin, paclitaxel as well as radiation therapy.

In May 2012, positron emission tomography was performed which showed increased uptake in the left supraclavicular node and paraoesophageal nodes (T3N1M0). Biopsy was performed, which showed tumour recurrence, which was positive for human epidermal growth factor receptor 2 (HER-2) antigen. The patient was started on capecitabine, oxaliplatin and trastuzumab. The patient received five cycles only, because he developed diarrhoea, weight loss (common side effects of capecitabine) and cardiac dysfunction (common side effects of trastuzumab).

In January 2013, the patient presented to the emergency department with complaints of lethargy and confusion, with subsequent transfer to intensive care unit. Brain MRI revealed an intra-axial haemorrhagic mass in the right temporal lobe with extensive vasogenic oedema (figure 1). The mass was resected, and it stained positive for CDX2, consistent with primary metastatic oesophageal adenocarcinoma (figure 2). Patient was scheduled for whole brain radiation therapy (WBRT) but became septic secondary to pneumonia while in the

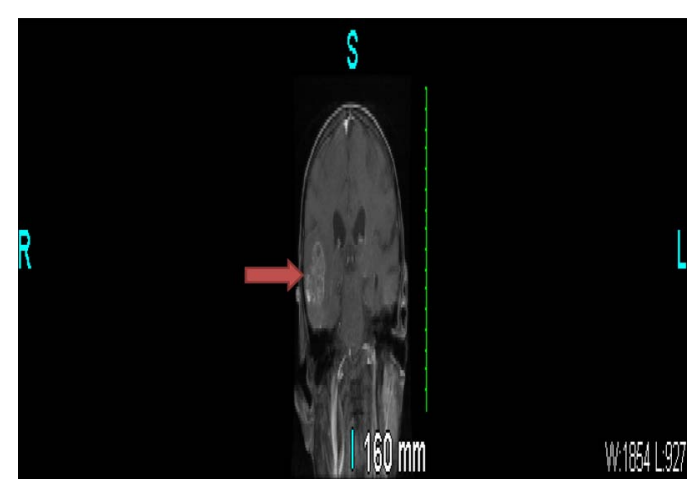

Figure 1 Intra-axial haemorrhagic mass in the right temporal lobe.

hospital. The patient was started on intravenous hydration and norepinephrine drip. Piperacillintazobactam, levofloxacin and vancomycin were started. Blood cultures were negative. The patient remained on blood pressure support until his family decided to discontinue the treatment. The patient was enrolled in hospice care.

Oesophageal adenocarcinoma is a common cancer with an estimated 17990 new cases and 15210 new oesophageal cancer-related deaths in 2013. ${ }^{1}$ Oesophageal adenocarcinoma most commonly affects the distal oesophagus and is common among people of Caucasian descent. ${ }^{2}$ The death rates are high, approaching $>75 \%$ at 5 years after diagnosis. ${ }^{2}$ Distant metastasis to the liver, lungs, adrenals and bones has been reported. ${ }^{3}$ However,
To cite: Nwankwo N, Mirrakhimov $A E$, Wind $K P$, et al. BMJ Case Rep Published online: [please include Day Month Year] doi:10.1136/bcr-2013009395

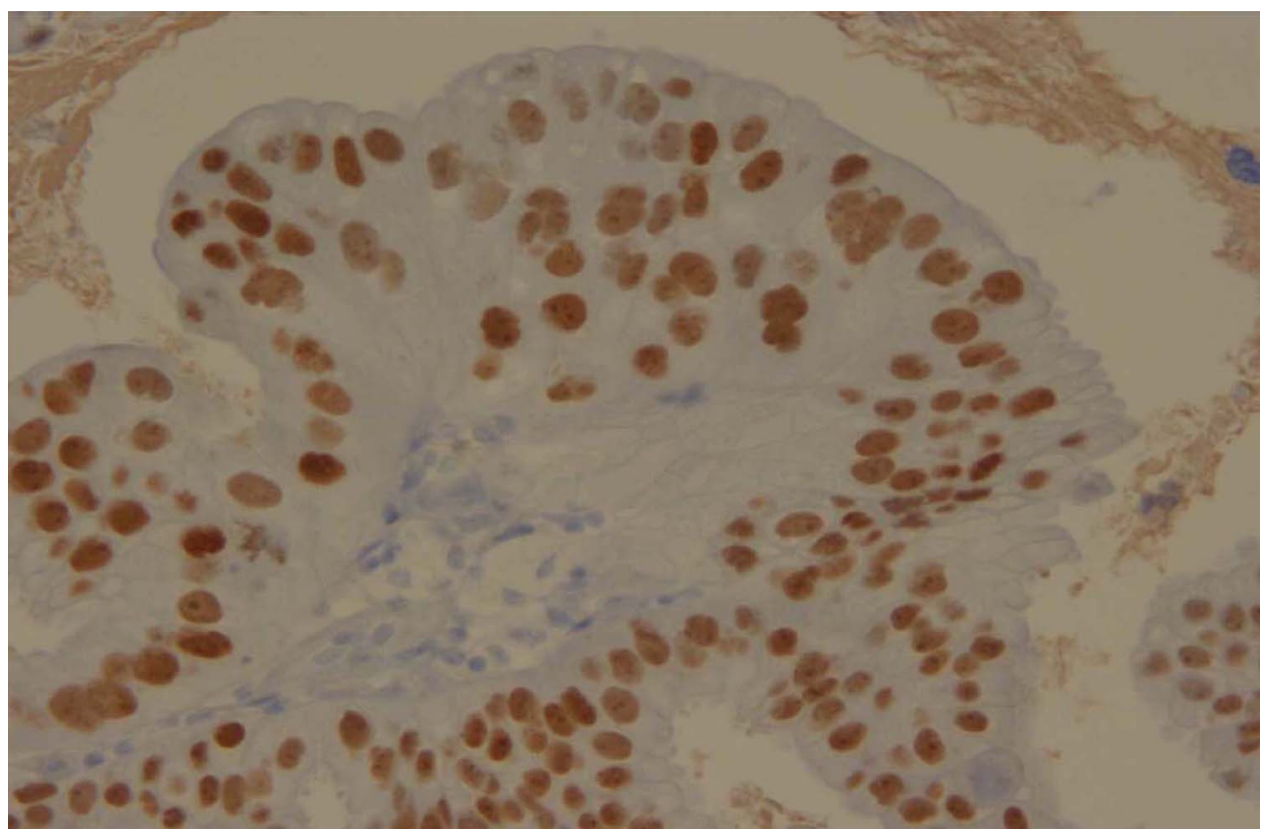

Figure 2 Brain biopsy consistent with metastatic oesophageal adenocarcinoma. 
distant metastasis to the brain is a rare finding with about 100 reported cases. ${ }^{4}$ This is likely because brain imaging is usually not performed in asymptomatic patients. Improved survival was noted in patients with single lesions who underwent resection and WBRT. ${ }^{5}$

In conclusion, oesophageal cancer though rarely found in the brain, can be treated if detected early.

\section{Learning points}

- Oesophageal adenocarcinoma is a gastrointestinal common cancer.

- Adrenal glands, bones, lungs and liver are the common distant metastatic sites of oesophageal adenocarcinoma.

- Brain metastases are rare in patients with oesophageal adenocarcinoma.

- Whole brain radiation therapy and resection (if the lesion is focal) were reported to be of clinical benefit in patients with oesophageal adenocarcinoma and brain metastases.
Contributors Each author contributed equally to this manuscript.

Competing interests None.

Patient consent Obtained.

Provenance and peer review Not commissioned; externally peer reviewed.

\section{REFERENCES}

1 American Cancer Society. Cancer facts and figures 2013. Atlanta: American Cancer Society, 2013. http://www.cancer.org/acs/groups/content/@epidemiologysurveilance/ documents/document/acspc-036845.pdf (accessed 27 Feb 2013).

2 Tougeron D, Richer JP, Silvain C. Management of esophageal adenocarcinoma. J Vasc Surg 2011;148:e161-70.

3 Meltzer CC, Luketich JD, Friedman D, et al. Whole-body FDG positron emission tomographic imaging for staging esophageal cancer comparison with computed tomography. Clin Nucl Med 2000;25:882-7.

4 Go PH, Klaassen Z, Meadows MC, et al. Gastrointestinal cancer and brain metastasis: a rare and ominous sign. Cancer 2011;117:3630-40.

5 Weinberg JS, Suki D, Hanbali F, et al. Metastasis of esophageal carcinoma to the brain. Cancer 2003;98:1925-33.

Copyright 2013 BMJ Publishing Group. All rights reserved. For permission to reuse any of this content visit http://group.bmj.com/group/rights-licensing/permissions.

BMJ Case Report Fellows may re-use this article for personal use and teaching without any further permission.

Become a Fellow of BMJ Case Reports today and you can:

- Submit as many cases as you like

- Enjoy fast sympathetic peer review and rapid publication of accepted articles

- Access all the published articles

- Re-use any of the published material for personal use and teaching without further permission

For information on Institutional Fellowships contact consortiasales@bmjgroup.com

Visit casereports.bmj.com for more articles like this and to become a Fellow 